\title{
Psychodynamic Psychotherapy with Suicidal Adolescents
}

Mark J Goldblatt (a), Stephen Briggs (b), Reinhard Lindner (c), Mark Schechter (d), Elsa

Ronningstam (a)

Corresponding Author:

Mark J. Goldblatt, M.D.

Address:

1105 Massachusetts Avenue, Suite 2C,

Cambridge, MA 02138. USA.

Tel: $617-354-4600$

Fax: 617-441-5533

Mark_Goldblatt@hms.harvard.edu
(a) Harvard Medical School, McLean Hospital
(b) University of East London
(c) Hamburg-Eppendorf University, Hamburg, Germany
(d) Harvard Medical School, North Shore Medical Center 


\begin{abstract}
:
Although the treatment of suicidal adolescents is complex and may be daunting to many clinicians, it continues to play an important role in suicide prevention. In this paper we use case material to address questions that arise in psychotherapy, including the contending priorities of understanding the suicidal act in order to prevent repetition, versus connecting emotionally with the patient in the therapeutic relationship; and the use of an evolving understanding of the complexity of suicide that develops over time as patient and therapist engage in a deepening relationship which fosters life-sustaining development and psychic change. We present a case description of a patient in later adolescence, who began intensive psychoanalytic psychotherapy after a suicide attempt and explore key components of therapeutic action. From this discussion we emphasise the relational aspects of the transference and countertransference that enables interpretation and increased therapeutic receptivity through collaborative interaction. We conclude that collaborative interaction is foundational for therapeutic action with suicidal adolescents.
\end{abstract}

Keyword: adolescent suicide, countertransference, therapeutic relationship, implicit relational knowledge, role responsiveness 


\section{Introduction:}

The treatment of suicidal adolescents is intimidating to many clinicians for various reasons, including the threat of death by suicide or a negative therapeutic reaction. Clinicians shy away from intense engagement with suicidal adolescents, in order to avoid the real and fantasized consequences that such therapies produce. Several factors play a role in this process, including the complexity of psychotherapy with these patients, institutional dynamics, and countertransference considerations.

Psychotherapy with suicidal patients is complex and varies depending of the ideology and practice of the clinician. Different approaches have developed across the world and this discussion will bring together views from three areas; USA, UK and Germany. Contemporary clinicians are faced with a range of differing theoretical points of view which may be contradictory to their institutional training. Published psychotherapy manuals and supervisors' advice may appear contrary to their own sense of appropriate therapeutic intervention. In addition, therapists face a bewildering array of choices in the moment-to-moment interaction with their patients. Institutional factors, family and peer group dynamics, and the therapeutic match contribute to the therapist's decision to undertake the treatment of the suicidal adolescent. Without adequate support, even seasoned clinicians may be inclined to seek out more simplistic practice modalities, or avoid taking on challenging patients.

Shame and helplessness are intrinsic components of the intense transferencecountertransference reactions that are commonly found in the treatment of suicidal adolescents. Countertransference shame may be in response to the therapeutic process itself as well to systemic or institutional features. Avoiding anticipated shame in response 
to peers in the therapeutic community and training institutions may explain why such patients are rejected or turfed to less senior (or less capable) clinicians. Most young patients sidestep clinical follow up or fall through the cracks created by obtuse health care systems, or financial disincentives. Premature termination of treatment, often seen in abbreviated therapies with suicidal adolescents, results in countertransference feelings of abandonment, confusion and anxiety (Berger, 1999) and further contributes to shame avoidance in the treatment of these patients. Countertransference avoidance may appear in many aspects of the treatment: rigid treatment formats defend against shame and blame; focusing on safety concerns alleviates countertransference anxiety but neglects the patient's associative process; intensive treatment with increased frequency of contact can be underutilized by following the rationale of encouraging self-development and adolescent autonomy. Understanding the suicidal process, and the interactive therapeutic relationship serves to increase the capacity for empathic relatedness, and enables clinicians to overcome countertransference resistances and feel competent to take on these challenging cases.

In this article we use case material to address dilemmas that arise in psychotherapy, including the need to understand the suicidal act in order to prevent repetition, versus the need to connect emotionally and relationally with the patient in his/her current state; and the different ways to work with the use of an evolving understanding of the complexity of suicide that develops over time, as patient and therapist engage in a deepening relationship. We emphasise the need to prioritize the therapeutic relationship, which we believe fosters life-sustaining development and 
internal structural change, especially in the face of hostility and a negative therapeutic reaction.

\section{Etiology of Adolescent Suicidality:}

In the UK, around 25,000 young people are admitted to hospital every year after selfharm (including suicide attempts), but most episodes (about 80\%) do not reach professional services (Hawton et al., 2012). Surveys in Europe show that around 10\% of girls and 3\% boys report an episode of self- harm (including suicide attempts) in the previous year (Hawton, et al., 2012), though these rates of reporting self-harm can rise as high as $28 \%$ (Brunner et al 2014). Once a person has self-harmed (including a suicide attempt) the likelihood that he or she will die by suicide increases $50-100$ times. One in 15 die by suicide within 9 years of the first episode (Kendall et al., 2011). Of those who begin self-harming (and suicidal behavior) in adolescence, about $70 \%$ cease self-harm within the adolescent period, and thus around 30\% continue into adulthood (Harrington, et al., 2006; Moran et al., 2012).

Suicidal behavior in adolescents and young adults is complex and multidetermined ${ }^{1}$. It is likely to occur during times of stress, often associated with family and individual crises, and may be transient or persist in a more chronic form. Thoughts of suicide may arise through a disturbance of the adolescent developmental process (Laufer, 1985; Anderson, 2008). Beneath the adolescent's often-ambiguous communications lies a struggle between attempting to engage with the tasks of development, and defensively retreating from the pains that development incurs. Taken in relational and social contexts,

\footnotetext{
${ }^{1}$ See Hawton et al., (2012) for a summary of factors associated with suicide and self-harm in adolescence.
} 
development can sometimes feel like catastrophic change. Although adolescents may adopt self-destructive defenses in an attempt to solve overwhelming developmental issues, they are also capable of overcoming apparently entrenched pathology (Waddell, 2006).

The act of suicide involves conscious and unconscious components and multiple meanings (Hendin, 1991). It represents an attack on internal and external objects with traumatic damage to both. Suicides occur to preserve the oedipal fantasy, as acts of revenge, or as self-regulatory efforts to protect fragility and manage emotions. Suicide may sometimes be seen as a reaction to the inability to bear disappointment; an indication of a loss of perfect control: fear of falling into non-existence, a black hole of despair; an effort to join a dead loved one; or a cry for help. Suicidal behaviors often represent an attempt to deal with an earlier trauma and the identifications that result from this trauma (Briggs et al., 2012).

Suicidal adolescents present material that is confusing and ambiguous, simultaneously indicating pathological defenses and attempts at developmental progress. Often this appears in the form of a catastrophic problem experienced during separation from parental figures, and focuses on problems of ownership of the body, thoughts, desires and aspirations. Suicidal motivation and meaning can appear to change at different points in the treatment. This plurality of meaning is partly the consequence of a deeper understanding developing within the therapeutic relationship, and also the changing world-view (or narrative) of the young person, as he/she changes, and grows (or matures). The material in adolescent psychotherapy is often binocular, reflecting the ambiguity and ambivalence of adolescent development, and has both a pathological and a 
developmental meaning. In some cases, re-actualization of early dependency and of oedipal conflicts as experienced in adolescence may stir suicidal wishes as a solution to unbearable distress.

One of the major tasks of this developmental stage is managing the experiences of separating from parental figures, and accepting ownership of one's body, thoughts, desires and aspirations. Adolescence is a critical phase for developing a sexual identity, including the gender specific body-identity. These themes are crucial to the understanding of adolescent suicidality, because threatening one's own life is a way to treat this changing body, which looks more like father or mother (the parental object) then ever before. Killing the body is one way to get distance from mother or father as external intrusive objects, or a way to take the body as a hostage in order to change the inner and outer objects relationships (Laufer, 1989). Suicide means both a selfdestructive attack on his internal and external relationships and a (maladaptive) attempt to secure greater separateness from parental figures. The changing understanding of the meaning of suicidal behavior is centrally located in relationships, firstly with parents and secondly with siblings and peers.

At times, adolescent suicidality may have a self-sustaining element (Maltsberger et al., 2012), but may tip from sustaining fantasy to actual plan and intent, especially at times of developmental challenge, such as separation from parents as the teenager moves away to college or independent work. Although consciously desired, this transition is fraught with difficulty.

For most young people self-harm is a transient phenomenon, borne out of an acute crisis that resolves relatively quickly. For others, suicidality persists over a longer period 
of time, leading to more chronic considerations. In fact many young people respond quickly to appropriate adolescent-centered psychotherapy. For some, suicide continues as a solution for their psychic problems or as conflicts arising from disturbance of the adolescent developmental process (Briggs, 2010).

\section{Psychotherapy:}

Emerging evidence suggests that psychodynamic psychotherapy is effective in reducing suicidal behaviour (Bateman \& Fonagy, 2008; Guthrie, 2001; Clarkin et al., 2007; Fiedler, et al., 2003; Rossouw and Fonagy, 2012). Crucial to the treatment of suicidal adolescents is how to engage the patient in the therapeutic process and which techniques are most useful to initiate psychic change. Slavin (1996), for example, showed that after a suicide attempt only about $50 \%$ of younger adolescents engaged in treatment lasting more than 6 sessions. Manualized treatment protocols for suicidal patients with borderline personality disorder find support for the therapist taking an active stance, with attention being paid to affects and safety issues during each session and between sessions (Weinberg, et al., 2010). However, it is not clear how to define an active stance. With suicidal adolescents the question becomes even more central, with the therapist having to weigh the effect of questioning the reluctant patient about safety issues, against the relative passivity of allowing the analytic material to surface; there is a similar tension between showing interest by asking questions versus allowing the patient to lead in setting the associative agenda.

The challenge for the "active therapist" is how to show the suicidal adolescent patient that he/she is interested in his thoughts and feelings, no matter how uncomfortable these may appear, on the one hand, while at the same time being very careful to not act 
overtly intrusively and controlling, and thus inviting an unhelpful parental transference, on the other hand. Young people appear particularly sensitive to these transference manifestations, which may trigger aversive reactions or negative therapeutic responses (Berger, 1999).

The therapist's ability to tolerate his/her own anxieties, affects and wishes to control the patient have to be balanced with the need for an engagement with the patient and shared interest in understanding the patient's inner world. The aim is to develop a therapeutic milieu which allows the patient to start to recognize and tolerate his own ambivalence, anxieties, wishes and desires and find his personal way into an active, social and related life.

With suicidal adolescents the therapist is faced with conflicting prescriptions about psychoanalytic neutrality. Freud (1912) advocated "evenly-suspended attention" (in German: "gleichschwebende Aufmerksamkeit"). In his paper on technique, Freud suggested "we should not give up the neutrality towards the patient, which we have acquired through keeping the counter-transference in check" (Freud 1915, p.164). Anna Freud (1936) suggested that "evenly hovering attention" should attend to issues arising from the id, ego and superego. Hoffer (1985) considered neutrality in relation to genuine involvement with the patient and added the question of "Neutral to what?" He suggested adding the 'explicit concept of external reality' (p. 792) to Anna Freud's position as a means to widen the neutral analytic field. Bion's (1967) notion that the analyst should be without 'memory or desire', as these impinge on the analyst's capacity to hear and be receptive to the patient, provides an additional counter-transferential context for considering neutrality and openness to the patient's communications. 
Some writers (e.g. Berger, 1999) suggest that the therapist cannot be neutral when it's a matter of survival. While the therapist cannot take away the option of suicide he/she is positioned as firmly life supporting. Suicidal adolescents may need explicit advocacy for life over self-destruction (Berger, 1999). The patient's self-harming wishes and past attempts exist as an external reality. Hoffer's (1985) concept of analytic neutrality to external reality suggests that focusing on the analytic hour and transference interpretations can have a mutative effect.

Suicide risk is increased when there is a sense of unbearable aloneness or intrapsychic desolation (Laufer \& Laufer, 1984) and interventions to address this isolation are crucial to preventing suicidal behaviour. Sometimes inter-session contacts in case of emergency and other supportive measures may convey sustaining support to alleviate acute suicidal distress (Goldblatt, 2008). At other times this may be accomplished through intensive frequency of sessions, three or more times a week. This intensity deepens the therapeutic process, but may intrude on the adolescent developmental process. On the other hand, therapeutic distance, arising out of countertransference hate can be suicide inviting (Maltsberger and Buie, 1974).

In a study of analytic outcome, Bush and William (2011) associated a good fit between therapist and patient and positive therapeutic alliance with successful treatment: "a caring and emotionally engaged analyst who possessed positive relational and personality qualities, used supportive techniques in addition to classical techniques, and pursued therapeutic as well as analytic goals"(p. 377) correlated with positive outcomes. Although this study did not deal with suicidal patients, it may reasonably suggest that these qualities are important in the treatment of suicidal adolescents. These results appear 
to recognize the importance of the "real" (non-transference) relationship, and underpin the efforts needed to establish and facilitate a therapeutic alliance. For self-hating patients the silent therapist can be easily viewed as endorsing the patient's own self-criticism, and can thus become a receptor for the annihilating projections (Asch, 1980; Kris 1981).

The therapist shows that he is open to involvement with the suicidal patient by placing him/herself at the patient's disposal, being engaged and interacting with the patient's defensive mechanisms as they manage complex feelings of mourning, guilt, shame, aggression and sexual desire. Oscillating between identification and rational reflective distancing, the therapist engages in this enactment (Klüwer, 2001; Jacobs, 2000) and is able to bear these emotions in him/herself, so that the patient can start to speak about suicidal ideas, plans and behaviour in a personal and attached way. In this process the therapist engages patients without attempting to control the behaviour, even while supporting life affirmations.

Adolescent suicide may be seen as an extreme solution to intrapsychic conflict: they want to end their life rather than not understand their suffering (Berger, 1999). However, understanding suicide dynamics alone is not enough to prevent suicide; an emotional and relational connection with the therapist is also needed. Effective psychotherapy with suicidal adolescents can be thought of as developing through a strong therapeutic relationship (Lindner \& Gerisch, 1997; Gerisch et al., 2000, Lindner, 2006).

\section{Clinical Case: ${ }^{2}$}

Sven was an18 year old male high school senior who made a serious suicide attempt while interviewing for university at his old hometown. He was hospitalized for

\footnotetext{
${ }^{2}$ Names and other identifying features have been changed to preserve confidentiality. Some case material overlaps with a separate paper addressing issues of suicidal group dynamics (Goldblatt et al., 2015)
} 
one week and returned home on the understanding that he would begin outpatient psychotherapy. This paper reflects this intensive psychoanalytic therapy, which lasted for 9 months, and ended when Sven decided to terminate treatment and go away to college in another city.

Sven grew up in a small town where his parents had gone to work after finishing their graduate studies. He is the younger of two siblings, with a 5 years older brother. His parents divorced when he was 5 years old, and his father left their hometown. Sven had little memory of his father. He says he was a happy child, involved in sports and schoolwork and did well academically.

He was not aware of his mother's romantic relationships until he was 15 , when she introduced him to the man she was dating. This man, Francis, lived in another state with his children from a previous marriage. Mother told Sven and his brother that after Sven completed high school she planned to move to be with Francis. However, this changed, and mother brought forward the move to live with Francis before Sven completed high school. Sven was enraged. He protested, but to no avail. He felt helpless to deal with this move, which he experienced as dragging him away from school and friends. He thought, "I'll do anything not to move, I'd rather kill myself", but he refrained from acting because he thought no one else would care for his beloved cat after he was gone. Reluctantly, he moved with his mother and began high school in the new state. He never gave up on his suicide plans, but waited for the right moment to act. $\mathrm{He}$ says his motivation to kill himself waxed and waned over time, and became stronger when he experienced pressures at school. 
Although intellectually gifted, Sven was a poor student and made little effort. He had a restricted social life and he spent most of his time playing games on the Internet. Perhaps his only friendship was with Eric, a charismatic youth who was involved in a turbulent relationship with Kamina, a girl in their class. Sven would ride the train each day to school with Kamina, and he felt they were getting close. Soon after school started in September of his senior year, Sven and his classmates went on a school weekend camping trip. During this time there was some distress involving Eric and Kamina. The next week, Sven and his mother drove back to their old hometown so that Sven could interview at a local university for placement, the following year. Sven reported that the interview went well. He decided that night to kill himself with a stash of painkillers that he carried with him just for that purpose. He says that the he realized "there was nothing I want in life". He took all the pills thinking it would kill him. He did not tell anyone, and went upstairs to his bedroom and tried to sleep. His mother came home and spoke with him, without realizing that he had overdosed. The next morning his mother had difficulty waking him from a nauseated, sedated state. He then admitted to taking all the medications. She took him to the Emergency Room and from there he was hospitalized.

During the hospitalization it was discovered that Eric had revealed to Sven his own plan to kill himself. On the day that Sven was leaving town for the college interview, Eric told Sven that he had just overdosed. Although he knew of Eric's previous serious suicide attempt, Sven decided not to tell anyone about Eric's dire situation. He turned off his own cell phone and left town. He decided to end his own life. He truly intended to die, and regretted surviving, adding, "I suppose it doesn't matter much". 
After his hospitalization Sven returned to school and $\mathrm{I}^{3}$ began to see him for psychotherapy. I offered him, and he accepted, intensive treatment, at a frequency of four times a week. Initially, Sven described his reactions to most things as 'always neutral'. Over the following few weeks, with my help he began to recognize his defensive style of avoidance of affect, and began to consider its consequences. He was able to recognize that his neutrality was an effort to diminish his feelings of hurt, shame and rage. He came to value his therapy as a place where he could learn something about himself. One of the things he felt he learned was that sometimes "I'm there, but not altogether there". This was one of the symptoms that he felt he needed help with. This feeling of social distance, isolation or withdrawal could sometimes worsen to a feeling of depersonalization, which was close to dissociation.

Over the next two months, Sven described his efforts to minimally get by at school, while still hoping to be admitted to the university where he had interviewed. $\mathrm{He}$ thought that he would be able then to return to his old hometown and live a fantasy life free of outside disturbance. However, he made no efforts with his schoolwork and fell further and further behind, thereby jeopardizing his graduation and entry into university. I wanted to encourage Sven's engagement in his life's tasks, so I tried to take an active stance, helping to explore his inner experience of home, school, mother, and friendships. I also encouraged him to try some Risperidone, (a novel antipsychotic medication), for the feeling of 'not altogether being there'. He refused.

Over time I came to recognize that my 'active stance' was not helpful, because it caused Sven to dig in his heels and resulted in both of us feeling frustrated and confused.

\footnotetext{
${ }^{3}$ The psychotherapy was conducted by one of the authors, and is described in the first person to increase immediacy.
} 
My need to be active was ostensibly driven by my understanding of the manualized literature on the treatment of suicidal patients with borderline personality disorder, previous experiences of working with suicidal patients and Sven's passivity. Beneath the intellectual rationale behind this approach was the comfort it gave me in dealing with Sven's withdrawal and efforts to remove himself from the consulting room. When I was able to better tolerate his indifference and potential failures, he became more able to talk about his life experience. This appeared to lead, after about two months to his agreement to a trial of Risperidone.

As the Christmas vacation drew near, it appeared that Sven had become more involved with his classmates. He appeared to be quite popular, despite his avowed indifference. His family planned an overseas Christmas vacation. As the holidays approached, Sven began to discuss the events that led up to his suicide attempt in the summer. He revealed that although Kamina was Eric's girlfriend, Sven felt that he had gotten close to her and in fact, they had begun a sexual relationship. Sven felt unbearably guilty because Kamina ended her relationship with Eric over the weekend of the school camping trip. He couldn't understand why Eric confided in him and treated him like he was his best friend. Twenty-four hours later Eric overdosed, and 24 hours after that came Sven's own suicide attempt.

While away for the holidays, Sven stopped his medication, and refused any contact with me. We had discussed the use of phone sessions or skype appointments, but he said he preferred to see how he managed alone during the break. I had the sense that it would be shameful for him to let others know that he was taking time to talk with his therapist. Following the Christmas break, Sven's mother sent me an email terminating the 
treatment. She felt that Sven had improved and only needed occasional visits. I encourage Sven to come in to talk it over. He seemed regressed. He recognized that his symptoms were indeed real, but felt they were intractable. His propensity to withdraw and dissociate was an attempt to keep away unpleasant feelings like guilt and shame, but, he felt this is the way he is and he did not want to put in the effort to change. He said he was not currently suicidal, but he seemed distant, monosyllabic and withdrawn. His school however insisted that he remain in treatment in order to continue attending classes and graduate. So he returned to therapy even though his mother felt he should be decreasing his involvement in treatment, and move on to other interests.

I came to realize that an implication of my 'active stance' was that Sven experienced me as acting like his overly intrusive mother. He needed his space, and would do almost anything to get it. As I began to recognize this, the negative maternal transference became less pronounced and a more empathic connection developed. Sven began to talk about how much he hated his family and his wish to never see them again after graduation. His fantasy was that when he went off to college, he would never need to have contact with his mother again. He would live his own life and not be bothered by her. It appeared that the suicide attempt was also a means of getting distance from a mother whom he perceived as overly involved, and from whom he could not have his own space to think, feel or have fantasies. A session at this point in his therapy illustrates these issues. 


\section{Session Transcript:}

Sven: "In middle school I looked forward to just living with my mom, but then she moved to be with Francis. I felt betrayed. She promised me we wouldn't move until college. That felt like a betrayal.

Tx: She chose her needs for Francis over yours.

Sven: I can't forgive her. I never will. She decided. 'I want to live with Francis' and therefore change Sven's life. Out of the blue. A whole new life for Sven. The move doesn't make sense. I have no friends there. She has no work there. Just Francis and his kids.

Tx: It provoked a high level of rage.

Sven: It's not as active as before. It fluctuates. The first few months were horrible. I was trying to find ways to return home. I begged my mom. I'd be visibly upset. Get me out of here. She wouldn't. What upset me was her reason: "It's too painful for me to not have you with me". Therefore she'd ruin my life, because it's too painful for her to not let me be happy. She was selfish. It was the same after my suicide attempt. She said, "I'm sorry I made you move. I didn't realize it would make you so upset”. You were OK with me being unhappy, so long as I didn't kill myself.

Tx: Nobody knew or didn't want to know how tough it was for you.

Sven: She didn't care until she realized my life was on the line. I knew I wouldn't be happy in the new town. I had to leave my friends and the things I did. It's not that anything makes me upset here, it's just losing what I had. 
About six months into therapy Sven described an incident at school. He noticed that Eric's phone indicated 'message waiting'. Sven thought it might be from Trish, a girl in their group who had been looking distressed. Sven picked up the phone and listened to the message that in fact, was from Trish. She was in the midst of a suicidal crisis. She was home alone, taking a deadly amount of medications. Sven jumped into action. He rallied his group of friends to tell a teacher, call Trish's parents and leapt into his car to drive out to her house, which was about an hour away. They arrived to find Trish passed out. Sven called the ambulance and her parents. He comforted another girl in the group who was having a hard time dealing with this suicide attempt. He attributed his ability to deal with Trish' suicide attempt to a change in his own mood and thinking. He was no longer suicidal and therefore felt empowered to help a friend.

I had become an important person in his life and, albeit expressing this somewhat obliquely, he would have felt uneasy reporting to me that he had not tried to help Trish. On the other hand, this also meant Sven had to deal with feeling 'too close', as became apparent in the last phase of his therapy.

As termination neared Sven kept re-assuring himself, and me; "I should be fine". He did not seriously think of suicide because "I allowed myself to become part of the group and consider them friends, as opposed to just people that I hang out with. Now I consider them friends. That's different."

Unfortunately I had to be away for a week at this point. Sven saw a colleague as a covering therapist. Following his return Sven's mother said that Sven preferred that Dr. E. and wanted to switch. At the next session Sven again was removed and I found it difficult to connect with him. 


\section{Session Transcript:}

He talked about his brother who had visited over the weekend. His brother was worried and that felt intrusive.

Sven: He didn't push all that hard to talk to me. I managed to avoid him.

Tx: Why not be direct?

Sven: It's awkward.

Tx: Your style of silence is an expression of your anger.

Sven: He's just trying to be close, and he's upset that I don't want him to be close.

His solution was to distance himself even further: applying what he called 'Sven's rules', which were, “if you can't follow Sven's rules then you get silence. If you get too close you're going to find yourself far away."

Tx: Some of the things I did recently might fall under this rule - e.g. talking with your school, suggesting you take medication, going away for a week.

Sven: (Hands over his mouth, pulling on his cheek, as if to control an inappropriate smile that had appeared). Last week I met with Dr. E. That was good. The idea of continuing to meet with him came up with my mother. It's awkward. He fills in for you and the patient switches over to him.

Tx: Maybe it's worthwhile understanding how upset you are with me.

Sven: I could be upset, but I just found it easier to talk with Dr. E.

The next session Sven talked about his hat, a baseball cap that he had worn consistently since he was twelve, as a sign of loyalty to his friend who had bought it with him. "I like to think I'm loyal because I want other people to be loyal to me." Tx: Yesterday we were talking respect, which is close to loyalty. 
Sven: I have one main rule for myself - if anyone tells me something private, I won't tell anyone else. The easiest way to make me dislike someone is if they tell someone else. Tx: I think very carefully about what I tell your mother. Sven: In therapy everything is confidential unless someone is in danger. But that's the whole point of therapy, to talk about the most important things.

Tx: You value respect and confidentiality, and you also see the value in psychotherapy. Not keeping one's word is a betrayal. So is not being there when you're supposed to be there. My not being here last week must have felt like a betrayal that would warrant a termination of our relationship. My not being here may also remind you in some way of the loss of your father. He was supposed to be there for you and he left. He went away. Not being there for you may be experienced as an unacceptable betrayal.

Sven: That's why I have 2 rules I try and hold myself to. (1) Don't spread information that you don't want spread. (2) Don't Lie. I really dislike lying. I've found clever ways to avoid the truth. I don't lie except to preserve rule \#1.

Tx: Integrity is key. Being there shows integrity.

Over the next 4 sessions Sven said goodbye. He was not going to continue with therapy after school ended. "I don't want to have to do anything". Tx: You will do anything not to feel controlled by your mother. Sven: I've basically decided I don't like my mother very much. Part of the reason for feeling suicidal was to cause her pain. She wants to see me successful and happy, more than I do. So preventing that hurts her more even if it hurts me. She takes pride in her 
children's experience. If I achieve something, do well in a test, it become her achievement more than mine. Also if I fail, it's her failure.

Tx: Having her son die is a great hurt.

Sven: I had to have considered my life as not so important. It only became an issue after we moved to away from home. She took all control away from me. Before we moved here I thought I had control and power. Once I'm no longer in her house, I can refuse all contact with her.

Sven terminated therapy feeling sad, but no longer suicidal. He had mixed feelings about his experience of therapy with me, but agreed to meet with a new therapist at his college-counseling center, and said he would call me if he felt the need.

\section{Discussion:}

Although this case material illuminates some of the reasons and motivations for Sven's suicidal feelings and behaviour, many ambiguities and uncertainties of meaning remain. In particular, have the reasons for his suicidal behaviour been worked through sufficiently, or can suicidality reemerge later, under particular circumstances.

Sven's accounts of his reasons for his suicidality differed during the course of his therapy. Significant amongst these accounts are his sense of betrayal by his mother, and his earlier feeling of abandonment by his father, early in his childhood. He was furiously entangled with his mother, whom he felt owned his achievements, and his suicide would have the effect of hurting her irreparably, and punishing her for this betrayal. He also experienced intense guilt, which he could not access directly, related to the sexual (and 
suicidal) triangle involving his best friend, (see Goldblatt et al., 2015 for discussion of the role of adolescent group suicidal behaviour).

Suicide - rather than maturation and development - became Sven's solution for the pains experienced in childhood and adolescence; pains involving separation, loss, exclusion, and difficulties in separateness and intimacy. Unable to find a more flexible way of dealing with not being in control of others, Sven thinks suicide is a solution. 'Sven's rules' itemise a narrow code of emotions and behaviour, involving the rejection and exclusion of those who do not follow his code. As the therapeutic relationship deepens, there is a ongoing elucidation of the complex meanings for Sven's suicidality, and he provides new information and forms new narratives of himself. The 'correct' explanation of the suicidality is not the essential piece; rather, suicide is multi-layered and organized around some central emotional experiences in his life, and his emotional and relational responses.

We note an overlap in themes from Germany, USA and UK in applying these views of suicidality to the discussion on countertransference and therapeutic action from our diverse perspectives. There is much common ground, with the additional focus in the USA on implicit relational knowledge (BCPSG, 2010), on containing self-destructiveness in adolescent development in the UK: (Anderson, 2008) and, in Germany, on applying the principle of "unconditional appreciation" within therapeutic relatedness (Götze 2000, p. 292).

\section{Countertransference Issues}

Acute suicidal states may provoke intense anxiety in the therapist, or may be experienced in the countertransference as feeling disconnected, distant, tired and without 
any emotional contact. In Sven's therapy, countertransference anxiety appeared early on in the therapist's effort to engage a withdrawn and suicidal young man. The therapist frequently found himself worried about Sven, pushing him to do the right things to care for himself. As this played out in the repeatedly frustrating experience of distance and conflict, the therapist came to recognize that Sven's responses provided an important understanding in the context of the relationship. As the therapist was able to realize his perceived intrusiveness, he was able to relate differently, allowing the patient to open up and reveal his hateful, aggressive impulses.

This material can be understood as relating to Sandler's (1976) discussion of the analyst's awareness of his countertransferential acceptance of the "role" that the patient has unconsciously evoked;

"the role-relationship of the patient in analysis at any particular time consists of a role in which he casts himself, and a complementary role in which he casts the analyst at that particular time. The patient's transference would thus represent an attempt by him to impose an interaction, an interrelationship....between himself and the analyst" ( $p$. 44).

Sandler focused on the analyst's awareness of his countertransferential acceptance of the "role" that the patient has unconsciously evoked. The therapist's ceasing to stay in this role creates an opportunity for interpretation and insight into the reasons that the patient needed him to respond in this particular way. As the therapist's responsiveness shifted, and as he found ways to move out of the "role" in which he was initially cast, the patient was able to experience and relate to him in a different way. 
In this case, the therapist had to work hard emotionally to understand the impact of his active stance and how these experiences connect with Sven's hatred of a mother he felt to be intrusive. Later, during the termination phase, when the therapist's one-week absence provokes Sven's wish to switch to another therapist, the buried pain of his father's deserting him becomes available for interpretation.

Although in this case interpretation was sometimes used as part of the therapeutic approach, a greater emphasis was on the therapist using reflections on countertransference experiences to make adaptations within the relationship between the therapist and patient. While Sandler emphasized interpretation in the context of role responsiveness others, following the work of Stern and colleagues (1998) have focused on working with implicit relational knowing to initiate a different way of relating within the therapeutic relationship. Stern described a "now moment" as something that happens between patient and analyst that is different from their usual way of relating, a change in the "implicit shared relationship." This provides an opportunity for a "moment of meeting," described as a "transactional event that rearranges the patient's implicit relational knowing by rearranging the intersubjective field between patient and therapist..." (BCPSG, 2010, p. 33). These are potentially mutative experiences in the intersubjective realm of implicit relational knowledge, just as interpretations can be mutative in the sphere of making conscious declarative knowledge.

Lyons-Ruth $(1999 ; 2006)$ similarly emphasized that early attachment and relational patterns with caregivers are experienced and encoded in the realm of implicit procedural knowledge, beginning before the infant has the capacity for symbolic and 
verbal representation. In psychotherapy the therapist hopefully engages the patient repeatedly in what she described as a "collaborative dialogue," characterized by:

"careful attention to the particular state of the other's intersubjective experience, open acceptance of a broad range of affects, active scaffolding of more inclusive levels of dialogue, and engaged struggle and intersubjective negotiation through periods when the other's mind is changing and new ways of relating are needed" (1999, p. 610).

These new and repeated "collaborative" interactions evoke and destabilize the patient's established non-conscious procedural rules, facilitating changes in what she called "enactive knowing." This new learning occurs primarily at an experiential, procedural level; it can be supported by, but does not require, cognitive insight ${ }^{4}$.

The therapist's recognition of the way the two of them were relating, and his capacity to step out of the role that the patient created for him and remain in a stance of empathic listening and reflective observation, allowed the patient to begin to experience a different relational possibility. Perhaps this can feel like a potentially risky interaction with a suicidal patient, since it can require the therapist to hold on to his anxiety about suicidality, without the potential relief that can sometimes be experienced, in making interpretations. Interpretation is replaced with patient, repeated engagement with reflecting, in the countertransference on relational aspects and their possible meaning. Thus, for example, a greater freedom in the therapeutic relationship occurred when the therapist recognised the implicit relational meaning of replicating Sven's mother's

\footnotetext{
${ }^{4}$ This discussion touches on an area of significant recent theoretical discussion, which includes different perspectives. In one of these, Fosshage (2011) for example, argues, unlike Stern and BCPSG, that there is a closer link to be made between the two dimensions of memory (declarative and procedural).
} 
intrusiveness. He does not interpret this, but adapts his position and approach, and an outcome is Sven's stronger, more coherent narrative of his sense of betrayal and its connection with his suicidal thinking. If patient and therapist can continue to engage in this way, and with ongoing interactions that evoke but disrupt the old relational patterns, the patient has a chance to engage further and then to begin to risk trying out a new way of relating with others. Perhaps enough of an experience of "collaborative interaction" can be truly suicide preventing.

Conscious reflection on relational patterns is a central aspect of countertransference (Fosshage 2011; Joseph, 1985). Bion's (1962) concept of transforming beta elements into alpha function has a similar emphasis on the role of countertransference reflectiveness for containing intense relational emotional experiences. Reflection on relatedness leads to the possibility of interpreting, and, also, adapting responses to the patient, with the aim of increasing collaboration. Two outcomes that can be identified in this case are the increased depth and texture of the patient's narratives, and the containment of emotions, which become named through the therapist's interventions and acceptance of the patient's attempts to put these into his own words.

By emphasising that working with, and within, the collaborative relational interaction is an essential component of therapeutic action with adolescent suicidal patients, the question of how to work with a suicidal adolescent patient moves away from recommendations to work more actively towards a more nuanced understanding of the role of working with the countertransference. Applying this to other therapies with suicidal adolescents, it can be important to provide interpretation alongside working 
within the countertransference to develop collaborative interaction, but the emphasis on collaborative interaction appears to us to be foundational.

\section{Conclusion}

The treatment of suicidal adolescents is challenging on many levels. Though it has been widely studied, there remains a need to develop further understanding of appropriate and helpful therapeutic action with these young people. After exploring the key literature, we presented a detailed case description that demonstrates the multi-layered meanings of suicidality. Through combining different theoretical approaches to adolescent suicidality, from across three geographical areas (USA, UK, Germany), in discussion, we focus on two key factors, which are interrelated; counter transference and understanding the reasons for suicidality. The latter is understood as multidimensional, and subject to changing narratives over time within the therapy. Suicide relates strongly to the experience of development in adolescence, especially with regard to intense feelings arising through relating to and separating from parental figures, and these processes can be distorted, and the effects exacerbated by, experiences of loss and exclusion. The impact of disturbance of development can thus generate suicidal solutions for deep conflicts and pains.

Working with the countertransference is crucial. We discuss this in relation to role responsiveness, drawing on both Sandler's (1978) work and the concept of implicit relational knowledge. We conclude that emphasising 'collaborative interaction' by attending through reflection in the countertransference to the therapeutic relationship has a most important place in therapeutic action with suicidal adolescents. This sits alongside interpretive work, which may be more or less actively used depending on the individual 
case. We thus move towards a more nuanced view of the therapeutic relationship, less prescriptive than previous accounts, for example, those recommending an active stance, and one that emphasises continual adjustments, through reflecting on the qualities of the relationship in the present. When working with suicidal adolescents, this therapeutic work often takes place in a complex, uncertain and often ambiguous relational field. The therapeutic relationship can often be experienced as tenuous and ambiguous, throughout therapy, and perhaps particularly at points of separation and in the ending, but is central to therapeutic treatment, and, thus, plays a key role in suicide prevention. 


\section{References}

Anderson, R. (2008) A psychoanalytic approach to suicide in adolescence In: Briggs, S., Lemma, A. and Crouch, W. editors. Relating to Self-Harm and Suicide: Psychoanalytic perspectives on Practice, Theory and Prevention. Routledge, 95-108.

Asch, S.S. (1980). Suicide, and the Hidden Executioner. Int. R. Psycho-Anal., 7:51-60. Bateman, A., Fonagy, P. (2004). Psychotherapy for Borderline Personality Disorder. New York, Oxford University Press.

Berger, M. (1999). Zur Suizidalität in der Adoleszenz. In G. Fiedler \& R. Lindner, (Eds.), So hab ich doch was in mir, das Gefahr bringt. Perspektiven suizidalen Erlebens.

Göttingen, Vandenhoeck \& Ruprecht, p. 29-65.

Bion, W. (1962) Learning from Experience, London, Maresfield

Bion, W. (1967) 'Notes on Memory and Desire.' The Psychoanalytic Forum 2: 272-273; 279-290.

BCPSG The Boston Change Process Study Group. (2010) Change in Psychotherapy: A Unifying Paradigm. The W.W. Norton and Co., Inc. NY.

Briggs, S. (2010). Suicide Prevention: The contribution of psychoanalysis. In A. Lemma, \& M. Patrick (Eds.), Off the Couch; Contemporary Psychoanalytic applications. London, Routledge, pages 46-66

Briggs, S., Goldblatt, M.J., Lindner, R., Maltsberger, J.T., and Fiedler, G. (2012). Suicide and Trauma: A case discussion. Psychoanalytic Psychotherapy, 26:1,13-33. 
Bush, M. \& ,William, M. (2011). Should supportive measures and relational variables be considered a part of psychoanalytic technique. Some empirical considerations.

International Journal of Psychoanalysis 92:377-399.

Campbell, D. (2008) The father transference during a pre-suicide state in Briggs, S., Lemma, A. and Crouch, W. eds Relating to self-harm and suicide; psychoanalytic perspectives on practice, theory and prevention, London, Routledge

Clarkin, J., Levy, K., Lenzenwegger, M., Kernberg, O (2008) Evaluating three treatments for borderline personality disorder; a multiwave study, American Journal of Psychiatry, $16,922-928$

Fiedler, G., Gans, I., Gerisch, B., Götze, P., Lindner, R., Richter, M. (2003).

Psychotherapie hilft: Effekte der psychoanalytisch orientierten Kurztherapie mit suizidalen Patienten. In P. Götze \& S. Schhaller (Eds.). Psychotherapie der Suizidalität. Forschung - Theorie - Praxis. Regensburg, Roderer-Verlag, pages 165 - 195.

Fosshage, J. (2011) How Do We "Know" What We "Know?" And Change What We "Know?" Psychoanalytic Dialogues, 21:55-74,

Freud, A. (1936). The Ego and the Mechanisms of Defence: The Writings of Anna Freud, Vol 2: New York: Int Univ Press, 1966

Freud, S. (1912) The Dynamics of Transference, Standard Edition, Vol XII, 97-108 Freud, S. (1915). Observations on Transference-Love (Further Recommendations on the Technique of Psycho-Analysis III). Standard Edition. Vol XII , 157-171

Freud

Gerisch, B., Fiedler, G., Gans, I., Götze, P., Lindner, R., Richter, M. (2000). "Ich sehe dieses Elendes kein Ende als das Grab": Zur psychoanalytischen Konzeption und der 
Behandlung Suizidgefährdeter. In Kimmerle (Ed.): Zeichen des Todes in der psychoanalytischen Erfahrung. Reihe Anschlüsse, Vol. 4. Tübingen, edition diskord, p. $9-64$.

Götze, P. (2000). Zur Suizidalität bei Borderline-Patienten. In O.F. Kernberg, B. Dulz \& U. Sachsse (Eds). Handbuch der Borderline-Störungen. Stuttgart, Schattauer, pages 281292.

Goldblatt, M.J. (2008). Hostility and Suicide: the experience of aggression from within and without. In: Briggs, S., Lemma, A. and Crouch, W. editors. Relating to Self-Harm and Suicide: Psychoanalytic perspectives on Practice, Theory and Prevention. Routledge, 95-108.

Goldblatt, M., Briggs, S., Lindner, R. (2015) Destructive Groups: The Role of Projective Identification in Suicidal Groups of Young People, British Journal of Psychotherapy, in press.

Guthrie E. et al (2001) Randomised controlled trial of brief psychological intervention after deliberate self-poisoning, British Medical Journal, 323, 135-138

Harrington, R., Pickles, A., Aglan, A., Harrington, V., Burroughs H., and Kerfoot, M. (2006) Early Adult Outcomes of Adolescents who Deliberately Poisoned Themselves, Journal of The American Academy of Child and Adolescent Psychiatry, 45, 337-345 Hawton, K. Saunders, K., O’Connor, R. (2012) Self-harm and suicide in adolescence, The Lancet, 379, 2372-2382

Hendin, H. (1991). Psychodynamics of suicide, with particular reference to the young. American Journal of Psychiatry, 148:1150-1158. 
Hoffer, A. (1985). Toward a definition of psychoanalytic neutrality. J. Amer. Psychoanal Assn., 33: 771-795

Jacobs, T.J. (2000) . Unbewusste Kommunikation und verdeckte Enactments im analytischen Setting. In U Streeck (Ed.). Erinnern, Agieren und Inszenieren. Göttingen, Vandenhoeck \& Ruprecht, pages 231-248.

Joseph, B. (1985) Psychic Equilibrium and Psychic Change, London, Routledge/New Library of Psychoanalysis

Kendall, T. Taylor, C., Bhatti, H., Chan, M., Kapur, N., On behalf of the Guideline Development Group (2011) Longer term management of self-harm: summary of NICE guidance, BMJ 2011;343:d7073 doi: 10.1136/bmj.d7073 (Published 23 November 2011), $1-3$

Klüwer, R. (2001). Szene, Handlungsdialog (Enactment) und Verstehen. In W. Bohleber \& S. Drews (Eds). Die Gegenwart der Psychoanalyse - die Psychoanalyse der Gegenwart. Stuttgart, Klett-Cotta, p. 347-357.

Kris, A.O. (1981). On Giving Advice to Parents in Analysis. Psychoanal. St. Child, $36: 151-162$.

Laufer, M. ed. (1985) The suicidal adolescent, London, Karnac.

Laufer, M. (1989). Adolescent Sexuality - a body/mind continuum. Psychoanal. St Child, $44: 281-294$

Laufer, M. \& Laufer, E. (1984) Adolescence and Developmental Breakdown : A Psychoanalytic View, London, Karnac Books 
Lindner, R. (2006). Suizidale Männer in der psychoanalytisch orientierten Psychotherapie. Eine systematische qualitative Studie. Gießen, Psychosozial-Verlag. Lindner, R., Gerisch, B. (1997): "Wollten Sie wirklich sterben?" - Zur Kontroverse psychiatrischer und psychodynamischer Aspekte der Suizidalität. Psychotherapie Forum Suppl. 5, 1: 65-68.

Lyons-Ruth, K. (1999). The two-person unconscious: Intersubjective dialogue, enactive relational representation, and the emergence of new forms of relational organization. Psychoanalytic Inquiry. 19: 576-617. Lyons-Ruth, K. (2006) The interface between attachment and intersubjectivity: perspective from the Longitudinal Study of Disorganized Attachment. Psychoanalytic Inquiry 26(4): 595-616.

Maltsberger, J.T., \& Buie D.H. (1974). Countertransference hate in the treatment of suicidal patients. Arch Gen Psychiatry.30 (5): 625-33.

Maltsberger, J.T., Ronningstam, E., Weinberg, I, Schechter, M., and Goldblatt M.J. (2010). Suicide fantasy as a life sustaining recourse. The Journal of the American Academy of Psychoanalysis and Dynamic Psychiatry, 38(4) 611-624 Moran, P., Coffey, C., Romaniuk, H., Olsson, C., Borschmann, R., Carlin, J. Patton, G. (2012) The natural history of self-harm from adolescence to young adulthood; a population based cohort study, Lancet 379; 236-43

Rossouw T. and Fonagy P. (2012) Mentalisation-Based Treatment for Self-Harm in Adolescents: A Randomized Controlled Trial, JAACAP, 51,12,1304-1313 Sandler, J. (1976). Countertransference and Role-Responsiveness. International Review of Psychoanalysis 3:43-47 
Slavin, J.H. (1996). Readiness for psychoanalytic treatment in late adolescence:

Developmental and adaptive considerations. Psychoanalytic Psychology, 13:35-51.

Stern, D.N, Saner, L.W., Nahum, J.P., Harrison, A.M., Lyons-Ruth, K., Morgan, A.C.,

Bruschweilerstern, N., and Tronick, E.Z. (1998) Non-interpretive mechanisms in

psychoanalytic therapy: the 'something more' than interpretation. International Journal of Psycho-Analysis 79:903-921.

Waddell, M. (2006) Narcissism - an adolescent disorder? Journal of Child

Psychotherapy, 32:21-34.

Weinberg, I., Ronningstam, E., Goldblatt, M.J., Schechter, M., Wheelis, J., and

Maltsberger, J.T. (2010). Strategies in treatment of suicidality: Identification of common and treatment specific interventions in empirically supported treatment manuals. The Journal of Clinical Psychiatry, 71.6:699-706. 